\title{
A NEW RESILIENT RISK MANAGEMENT MODEL FOR OFFSHORE WIND TURBINE MAINTENANCE
}

\author{
Ayhan Mentes ${ }^{\mathrm{a}, *}$, Osman Turan ${ }^{\mathrm{b}}$ \\ a Istanbul Technical University, Faculty of Naval Architecture and Ocean engineering, Department of \\ Shipbuilding and Ocean engineering, Istanbul Turkey \\ ${ }^{b}$ University of Strathclyde, Department of Naval Architecture, Ocean and Marine Engineering, 100 Montrose \\ Street, Glasgow United Kingdom \\ *Corresponding Authors
}

\begin{abstract}
The objective of this study is to implement the principles of Resilience Engineering (RE) for the maintenance management of Offshore Wind Turbine (OWT) systems by taking into account human and organizational factors. Resilience concepts are integrated into existing maintenance management elements and a resilient model is developed and applied to OWT in order to manage the maintenance related risks. The four main capabilities proposed by RE, i.e. responding, monitoring, anticipating and learning, are linked to a three level resilience system in order to prevent or mitigate OWT maintenance failures. The paper presents the applicability and effectiveness of RE in preventing accidents/incidents and system failures, and learning activities.
\end{abstract}

Keywords: Risk Based Maintenance; Offshore Wind Turbines; Resilience Engineering; Human Factor; Barrier Management; Risk Management. 


\section{Introduction}

Wind energy plays a crucial role in improving the renewable power sources of a country/region and in reducing the greenhouse effect, and maintaining ecological balance. Global installed wind capacity was estimated to be around 370 Gigawatt at the end of 2014 (WWEA, 2015). Recent regulatory and economic developments in the EU have significantly changed the wind energy perspective for the next 15 years. As a result, wind energy has been the fastest and strongest growing renewable energy resource of power production in the world. The European Wind Energy Association (EWEA) updated the vision of European wind energy industry for 2030. EWEA expects $320 \mathrm{GW}$ of wind energy capacity to be installed in the EU by $2030-254$ GW of onshore wind and $66 \mathrm{GW}$ of offshore wind (EWEA, 2015).

However, the current cost of offshore wind energy is much more expensive compared to land based power alternatives. Wind turbine operation and maintenance (O\&M) represent an important part of the wind power production cost due to a large number of component failures. Indeed, the operation and maintenance costs represent $20 \%-25 \%$ in the lifetime of a wind turbine. Actually, these costs are limited to $10 \%-15 \%$ when the wind turbine is almost new, but they increase to at least $20 \%-35 \%$ by the end of its lifetime (EWEA, 2009). High reliability and the safety of wind turbines and their components is one of the prerequisites for the economic exploitation of onshore and offshore wind farms. For offshore wind farms under harsh weather conditions, the demand for reliable and safer wind turbines is even more important since both maintenance and repair costs are very high. Moreover, O\&M costs can be expected to increase further when wind farms are placed at deeper water depths (EWEA, 2009). Also, the maintenance cost of offshore wind turbines contributes significantly in the cost of a $\mathrm{kWh}$. That cost may be lowered by the application of effective reliability and risk based maintenance strategies.

A wind turbine is a complex power generating system consisting of several structural, electrical, and mechanical components interacting with environmental, human and organizational factors. Its efficiency and availability depends on its reliability, safety levels and the compatibility of its components with the factors mentioned above. In order to increase the reliability and safety of offshore wind turbines, risk-based maintenance decisions can be adopted to reduce OWT failures and hence minimise the total expected life cycle costs. However, the modelling of the relationship between maintenance and safety management is 
not an easy task, especially when human factors play an important role during the maintenance phases of offshore wind turbines.

Research gaps exist in identifying and developing the most suitable risk analysis and safety assessment model for Risk Based Maintenance and Operation of Offshore Wind Turbine systems. Furthermore, emerging gaps can be encountered when information varies, conditions change, or new kinds of events occur during operations in marine and offshore domain. Most traditional risk assessment approaches are inefficient in terms of coping with risks in complex socio-technological systems. These techniques have some limitations when incorporating a new link among risk models, human and organizational factors in order to study modern complex technological systems. Therefore, there is a need for a consistent model to be used for optimal Risk Based Maintenance, which takes into account human and organizational factors for OWT safety management.

The aim of this paper is to adapt and implement Resilience Engineering (RE) principles to the maintenance management of Offshore Wind Turbine (OWT) systems by taking into account human and organizational factors. This paper intends to investigate what RE principles and techniques exist in literature and how these RE principles can be used in the OWT industry to enhance system reliability, availability and safety whilst minimising the costs. A review of human factors in incidents/accidents as well as the classification of human factors is carried out. Resilience Engineering principles are introduced and then typical failures in OWT are categorised. An Integrated Resilience Engineering based O\&M framework for OWT is proposed so as to enhance the reliability of OWT systems by focusing on human and organisational factors.

This paper is divided into six sections. A literature survey about maintenance related accidents, human factors and its role on accidents, as well as information about safety barriers are given in section 2. The Principals of Resilience Engineering are introduced together with its cornerstones in section 3. Section 4 presents the stages of the proposed resilient model. In Section 5, the application of Resilience Principles to the Offshore Wind Turbine maintenance is outlined. Section 5 also discusses how the resilience of the OWT maintenance management can be improved. In Section 6, a summary of this research and concluding remarks are presented. 


\section{Human Factors and Resilience Management in Wind Turbine Maintenance}

A wind turbine is a power generating system which is driven by the kinetic energy of the wind. A typical wind turbine comprises of 8000 different components, which can be categorised according to the tasks they are related to (EWEA, 2009). A commercial offshore wind turbine consists of a foundation, transition piece, tower, nacelle and blades. All the power production units are located in the nacelle in order to protect them from extreme weather conditions. The blades, rotor hub, gearbox and brake are part of the system which maintains the physical integrity of the wind turbine and controls the rotation speed of the system between safe operating parameters (Robinson et al., 2013).

Humans play an important role during the design, installation, production, maintenance, and operation phases of these systems. Human errors are the main cause of accidents and component failures. Human errors in maintenance are normally due to incorrect inspection, diagnosis, repair or installation of the equipment. Two specific examples of maintenance errors, amongst many others, are the incorrect calibration of equipment and the wrong grease application at appropriate points of the equipment.

\subsection{Wind Turbine Accidents}

As expected more accidents occur as more turbines are built and the number of recorded accidents reflect this. An average of 33 accidents per year are observed between 1998 and 2002, 81 accidents per year between 2003 and 2007, 144 accidents per year between 2008 and 2012, and 167 accidents per year between 2013 and 2017 (Caithness Windfarms Information Forum (CWIF), 2018). More detailed information on wind turbine related accidents and incidents can be found on CWIF web page (CWIF, 2018). Fig 1 presents the analysis of 2186 accidents related to wind turbines (Figure 1).

Data based on US reported claims in 2012, shows that blade damage and gearbox failure account for the greatest number of losses of wind turbines - accounting for $41.4 \%$ and $35.1 \%$ of the total claims reported respectively. Damage to generators $(10.2 \%)$ and transformers $(5.1 \%)$ are ranked third and fourth, while damage to foundations is ranked fifth. Moreover, the top two most frequently reported causes of loss of power generation were cited by the initial insurance claims as poor maintenance (24.5\%) and lightning strikes $(23.4 \%)$, followed by 
design defects (11.5\%), wear and tear (9.3\%) and mechanical defect (6.2\%) (GCube, 2013). Fig 2 shows that gearboxes caused longest downtime per failure (Windstats Reports, 2009).

Maintenance is particularly vulnerable to errors as maintenance tasks are often complex and involving the frequent removal and replacement of a variety of components in a limited time frame (Pennie et al., 2007). A non-reporting culture in some sectors of the industry has tended to discourage the reporting of maintenance incidents. Approximately $60 \%$ of the maintenance personnel surveyed by Hobbs and Williamson (2008), reported that they had corrected an error made by another technician without documenting their action. Windtech International reported that a survey of 75 wind farm operators in the U.S. in 2008 found that $60 \%$ of turbines may be behind the required critical maintenance schedule due largely to a shortage of qualified turbine technicians (Raftery, 2012). In the wind turbine industry, failures are frequently reported on overloading, overheating, bad designs, etc. but the statistics taken from a manufacturing company show that $40 \%$ of wind turbine failures are due to human factors (Fig 3).

\subsection{Human Factors Analysis and Classification}

An influential classification of the different types of information processing in industrial tasks was developed by Rasmussen (1979). This scheme provides a useful framework for identifying different types of errors, which are likely to occur in different operational situations. The classification system is known as the skill, rule and knowledge based approach. The terms skill, rule and knowledge based approach refer to the degree of conscious control exercised by the individual over his or her activities.

Some taxonomies of human error, which have been developed and used in some industries, can be found in Human Reliability Assessment literature. A well-used taxonomy was proposed by Swain (1982), and Swain and Guttman (1983), who distinguished between the three main categories of errors as listed below:

(1) Errors of omission - Required action is not carried out.

Entire task omitted;

Step(s) in task omitted.

(2) Errors of commission - Required action is performed incorrectly.

Selection error - Wrong object selected.

Sequence error - Acts carried out in wrong sequence.

Timing error - Acts carried out too early or too late. 
Qualitative error - Acts carried out to too great or too little an extent, or in the wrong direction.

(3) Extraneous acts - Wrong or unnecessary acts are performed. This taxonomy is fairly general in its descriptions of error and is therefore able to cover most possible types of visible error.

Hollnagel (1990) distinguishes between external and internal error mechanisms by referring to them as the genotype (internal) and phenotype (external) of erroneous actions in his taxonomy. Rasmussen (1987) and Hollnagel (1998) argue that taxonomies of human error for error analysis techniques need to take into account the internal (psychological) causes of errors when classifying them. Reason (1990) offered a comprehensive treatise on the nature of human error in his book 'Human Error' and he examined errors in four main categories:

Unsafe acts of operators;

Preconditions for unsafe acts;

Organisational influences;

Unsafe supervision.

Reason's model, developed for analysing a wide range of organizational and operational accidents, is widely used and accepted. This model is generally named as the Swiss Cheese Model. Swiss Cheese represents the deficiencies in a system's defences by holes in slices looking like Swiss Cheese. Reason's model describes interaction between system wide latent conditions (e.g. maintenance failures, inadequate training and procedures) and unsafe acts carried out by human operators/technicians and their role in accidents. Most people think of safety as the absence of accidents and incidents. In this perspective, which is termed Safety-I, safety is defined as a state where as few things as possible go wrong. According to Safety-I, things go wrong due to technical, human and organisational causes - failures and malfunctions (Eurocontrol, 2009). Humans are therefore viewed predominantly as a liability or hazard. Safety management should therefore move from ensuring that 'as few things as possible go wrong' to ensuring that 'as many things as possible go right'. This perspective is termed SafetyII and relates to the system's ability to succeed under varying conditions. According to SafetyII, the everyday performance variability needed to respond to varying conditions is the reason why things go right. Humans are consequently seen as a resource necessary for system flexibility and resilience (Eurocontrol, 2009).

\subsection{Barrier Analysis and Modelling for OWT maintenance}


A barrier is employed to control, prevent, or slow down the hazard from reaching the target. Barrier analysis is used to identify hazards associated with an accident and the barriers that should have been in place to prevent it (Sklet, 2004). Reason's Swiss cheese model depicts how accidents occur in spite of the use of safety barriers. As in Swiss cheese, there are holes representing the weak spots of safety barriers and the likelihood of failure. In order to strengthen the barriers, it is important to know where and how big the holes are. This highlights the importance of the integrity of safety barriers.

Different barriers have been widely utilised in several industries for many decades and some would even say that they have been utilised forever. Hollnagel (2004) proposes a classification based on the nature of the barriers using four categories: material/physical, functional, symbolic and regulatory barriers. Material/physical barriers physically prevent an event from taking place, functional barriers perform an active function (e.g. equipment alignment), symbolic barriers require interpretation (e.g. procedures, signs, instructions) and regulatory barriers are not physically present (e.g. checks, rules, safety principles). Favaro and Saleh (2017) expressed the "defence-in-depth" as a fundamental safety principle for the design and operation of nuclear power plants. In its bare essence, "defence-in-depth" consists in the design and implementation of multiple safety barriers. They proposed in their work a safety principle termed "observability-in-depth" to prevent some hazard-concealing potential of "defence-indepth" from materializing.

Furthermore, barriers are classified as physical and non-physical (ISO 17776, 2000), hard and soft defences (Reason, 1998), and technical or human factors-organisational systems (Svenson, 1991). A recommended way to classify barrier systems is given by Trbojevic (2008). The classification includes technical barrier (e.g. emergency shut-down valve, early warning system, etc.), human/organisational barrier (e.g. inspection, monitoring, controlling instruments operator control, supervision, etc.) and fundamental barrier (e.g. design review, commissioning review, procedural review, operational review, competence assurance, good health of workforce, etc.). Also, the Aramis project defines safety barriers broadly, so that they include not only physical barriers, control instrumentation and active safety barriers, but also human actions which implement the whole or parts of the safety functions (Hourtolou and Salvi, 2003). 


\section{Resilience Engineering (RE)}

Resilience is the ability of systems to mount a robust response to unforeseen, unpredicted, and unexpected demands and to recover, resume or even continue normal operations. Resilience as defined by Woods and Branlat (2011) is a system's potential for adaptive action in the future when information varies, conditions change, or new kinds of events occur, any of which challenge the viability of previous adaptations, models, or assumptions. Resilience Engineering (RE) is used to represent a new way of thinking about safety. RE is a paradigm which focuses on helping people to cope with complexity when they are under pressure to achieve success (Woods, 2006). Over the last decade, RE has been proposed as an alternative for the management of safety in complex socio-technical systems. RE represents a new ways or horizons about safety. Established risk management approaches are based on hindsight and emphasise error tabulation and calculation of failure probabilities. However, RE looks for ways to enhance the ability of organisations based on their strengths to create processes that are robust yet flexible, to monitor and revise risk models, and to use resources proactively in the face of disruptions or ongoing production and economic pressures (Dekker et al., 2014).

Resilience describes the organisation's approach in anticipating and circumventing threats to its existence and primary goals. According to Hollnagel (2006), a system or an organisation must have four abilities in order to be resilient, (See, Fig 4).

RE provides a supplementary perspective on safety assessment and management, and offers possible resilience assessment techniques to complement existing procedures or tools. Adopting RE does not require that existing practices are discarded completely, nevertheless it does mean that existing practices are looked at in a different way, which in turn may change how they are applied, as well as the way in which their results are interpreted (Eurocontrol, 2009).

The first publications about RE were made in 2003 (Woods, 2003; Woods and Wreathall, 2003). However, RE became more widely known to the academic society with the first Resilience Engineering Symposium in 2004, and also due to the publication of a book based on that meeting (Hollnagel and Rigaud, 2006). Many academics have attempted to use and develop RE and its principles for modelling systems to make them resilient to shocks or disasters. Two significant literature surveys are presented by Righi et al. (2015) and Bergström et al. (2015). Righi et al. (2015) proposed a research agenda for RE and identified six research 
areas: theory of RE; identification and classification of resilience; safety management tools; analysis of accidents; risk assessment; and training. Bergström et al. (2015) examined how the peer-reviewed safety science literature (a) formulates the rationale behind the study of resilience; (b) constructs resilience as a scientific object; and (c) constructs and locates the resilient subject.

Woods (2006) and Jackson and Ferris (2013) have identified four attributes of a system that the RE principles seek to achieve as follows:

Capacity: The ability of the system to survive a threat.

Flexibility: The ability of the system to adapt to a threat.

Tolerance: The ability of the system to degrade gracefully in the face of a threat.

Cohesion: The ability of the system to act as a unified whole in the face of a threat.

In order to clarify the resilience concept in systems, Wears and Morrison (2013) proposed resilient behaviours in three levels: 1) simple, homeostatic response; 2) second order response involving more novel adaptations; and 3) a third order response characterized by learning. The simplest level is a simple homeostatic response and it can be labelled as Level 0 resilience, because they would not consider it resilience at all in the RE community. After all, it uses the numeral 1 to signify that resilience at the second stage is essentially a first order response to some disturbances and is labelled as Level 1 resilience. Level 2 resilience is a second order response to a disturbance that is either untried, or not well-managed by first order processes. Level 2 involves more than just responding, but also engages the activities of anticipation and monitoring, since a second level response is often aimed at preparing for the recurrence of a similar threat or opportunity. In level 3, the system has gone through enough second order experiences with appropriate and relevant feedback (March, Sproull and Tamuz, 1991), and it may then begin to learn how to do second order response well. This not only increases the effectiveness of second order responses, but also contributes to building margin (Stephens, 2010).

\section{Proposed Resilient Management System Model for OWT}

By taking into account underlying causes of human and organizational factors, a systematic multi-stage model is developed to implement Resilience Engineering (RE) principles to risk based maintenance of OWT (Figure 5). The model contributes to efficient risk management of 
Offshore Wind Turbine (OWT) systems and the key steps of the proposed model are given as follows:

Stage 1: Modelling and planning of the OWT maintenance system: In this stage, problem is defined, goals and objectives are identified and data related maintenance failures are gathered. Stage 2: Determine and analyse main direct causes and underlying causes of OWT maintenance failures, taking into account human and organizational factors: At this stage, main direct causes and underlying causes of maintenance related failures are defined.

Stage 3: Specify technical, human/operational and fundamental safety barriers: At this stage, multiple and independent safety barriers are employed to control risks, and to prevent or mitigate the consequences of unexpected events occurring in OWT maintenance activities.

Stage 4: Identify resilience components and risk management system key factors (HAZID): The cornerstones of RE are underlined and significant failures are defined. The abilities or qualifications of the resilience components are presented at this stage.

Stage 5: Allocate levels of resilience for the safety management system: First order, second order and third order resilience systems are designated at this stage. First order resilience is defined as Level 1 and not considered as part of resilience. Second order and third order resilience (Level 2 and Level 3) are the most important and therefore are corner stones of the resilience.

Stage 6: Make inferences and decisions, identify uncertainties, outcomes and continual development: This stage gives properties of a truly resilient maintenance management system that the system absorbs, adapts, adjusts and survives at all three resilience levels. It also responds to how the resilience of the OWT maintenance management can be improved, while highlighting the limitations of the proposed resilient model.

\section{Offshore Wind Turbine Maintenance Management}

The Offshore Wind industry has been continuously installing new and bigger offshore turbines, which are increasingly further away from the shore. However, the experience of the Wind Energy Industry with offshore wind is very limited and recent, since most of the companies have extensive experience only with land based wind turbine operations. Offshore wind companies, which have been trying to reduce the cost of electricity production from offshore wind turbines, started to realise that installing offshore wind turbines and performing O\&M activities on offshore wind turbines are very challenging and significantly different than O\&M activities on land based wind turbines. Accessibility difficulties for technicians due to the 
weather conditions, technical limitations of Crew Transfer Vessels (CTV) and limited weather windows due to transit time and availability of daylight not only increase the cost of O\&M but also reduce the electricity production due to the longer unavailability of offshore wind turbines. Furthermore, due to the current O\&M contract types, offshore wind farm operators have limited access to O\&M and failure data. It becomes more challenging to develop O\&M strategy for offshore wind farm operators without in-depth analysis of the data. Despite all these challenges, offshore wind farm operators need to develop a more resilient O\&M strategy to enhance the reliability of the systems, the quality of the maintenance, and the accessibility, while increasing the electricity production as part of reducing the cost of electricity production.

In this study, RE principles are designated for OWT maintenance in order to prevent or mitigate failures and improve safety management of an OWT system. For that purpose, a systematic multi-stage model is developed and applied to risk based maintenance of OWT by taking into account underlying causes of human and organizational factors. The stages of the proposed method are performed step-by-step as follows:

Stage 1: Maintenance is essential for the OWT industry. It involves a complex organizational structure in which each maintenance technician performs varied and challenging tasks with limited time, minimal feedback, and sometimes under difficult environmental and weather conditions that making accessibility to the offshore wind turbines very difficult and in some cases impossible for technicians. Human factors influence wide range of maintenance activities, and they affect everything technicians do on the job, from communicating effectively with the maintenance team to ensuring that they have adequate equipment to work accurately and efficiently as well as the quality of the maintenance performed.

The main objective of the study is to help the OWT industry to better identify their major operational and maintenance weaknesses and constraints in order to improve risk management and maintenance operations under the condition of limited time.

When human factors are in the centre of OWT maintenance safety, quality, capacity, attitude, insight and training of personnel are seen as important factors. The organizational culture, organizational climate, managerial model, decision-making pattern, and safety culture will also affect the outcome. Accidents are usually linked to organizational or managerial issues which include a series of errors and are sometimes difficult for frontline personnel to recognize or control. 
Stage 2: The paper focuses on significant organizational and human risk factors during OWT maintenance, causes of accidents/incidents or failures, which affect complete loss of offshore wind turbine energy conversion capability. Therefore, some types of accidents (e.g. human loss, injury etc.) are omitted in the current study.

In the OWT maintenance operations, human factors can be considered under four main categories as (Reason, 1990): unsafe acts of offshore maintenance technicians, preconditions for unsafe acts, organisational influences and unsafe supervision. Unsafe acts of offshore maintenance technicians are taken into account as skill based errors, violations, judgment and decision making errors, and perceptual errors. Preconditions for unsafe acts are considered as conditions of technicians and maintenance personnel factors. Organisational influences include resource management and organisational processes. Unsafe supervision includes inadequate supervision and supervisory violations.

OWT companies' reports, $\mathrm{PhD}$ dissertations, OWT technicians' manuals, accident investigation reports and journal papers in literature were intensively analysed. Furthermore, experts and maintenance managers from offshore renewable companies were consulted through a number of workshops, in terms of O\&M related issues that they have been experiencing with OWT (Dalgic, 2015, Dalgic et al, 2015 a Dalgic et al, 2015 ${ }^{\mathrm{b}}$ ). As a result, the potential main results of an OWT hazard, and the main direct causes and underlying causes of maintenance related gearbox failures were compiled into a number of lists. The potential main results of OWT hazards are listed in Table 1 and the main direct causes are in Table 2. Also, the potential causes of organizational risk factors were given in Table 3.

The maintenance element of the O\&M of plants is a combination of all technical, administrative and managerial actions and involves routine and non-routine observation, service and repair. There is more than one type of maintenance such as preventive maintenance, corrective maintenance, condition-based maintenance etc. in Offshore Wind Industry. Preventive maintenance is carried out before failures occur in order to avoid or mitigate the consequences of potential failures of OWT equipment.

Some of the underlying causes are examined for gearbox failure of OWT as a test case in this study (Table 4). Maintenance activities themselves may trigger events which can lead to major accidents. As presented in Table 4, skill-based errors are the most common mistakes, which 
are followed by judgment and decision making errors, routine, supervisory, organizational process violations or influences, oversights and lastly adverse mental state errors. These aspects should be taken into account when planning or conducting risk management related to OWT Gearbox component.

Stage 3: Operation and Maintenance (O\&M) plants are intended to support the lifetime operation of wind farms to minimise any disruption to energy generation and maximise output. The operations side of the O\&M facility involves monitoring the performance of the wind farm, and organising maintenance schedules. Maintenance of equipment must be considered, not only during the production part of its service life but also throughout its technical life. Preventive maintenance is carried out before failures occur in order to avoid or mitigate the consequences of potential failures of OWT equipment. The different types of preventive maintenance and routine periodic tasks and inspections for wind turbines are given in Table 5.

Deficiencies with preventive maintenance, routine periodic tasks and inspections can lead to failures. Deficiencies include inadequate mechanical integrity programs, delayed or deferred preventive maintenance, ageing infrastructure of equipment, lack of oversight and training, as well as inadequate policies and procedures at Offshore Wind Turbine Farms. In order to prevent or mitigate underlying causes of failures and to improve safety, technical, human/organizational and fundamental barriers can be used for OWT maintenance (Table 6). Human and organizational barriers, which directly affect the performance of other barrier systems, have a significant impact on the risk management of OWT maintenance.

When linking a barrier to safety critical tasks, one should ensure that the barrier is operational at all times and someone is responsible for the task. Care should be taken to distribute the responsibilities so that persons, who maintain, inspect, and control can be certain of the reliability and availability of the barriers.

Multiple and independent safety barriers can be employed to control risks, and to prevent or mitigate the consequences of unexpected events occurring during maintenance activities; but this may fail due to barrier deficiencies or inherent challenges. Therefore, it is necessary to analyse maintenance activities in detail and pay attention to potential latent errors and problems related to organizational and human factors. This may enhance risk management capabilities and the effectiveness of the barriers. To realize this aim, RE techniques and its principles can be assigned to OWT maintenance, and the cornerstones of RE principles can be utilised as effective barrier systems to improve OWT reliability and safety. 
Stage 4: RE techniques are important tools to increase resilience characteristics for OWT maintenance. In this step, the cornerstones of RE are underlined and significant failures are defined. The potential failures of the OWT gearbox system are given as twenty-seven underlying causes in Table 4. Resilience components are identified as responding (knowing what to do), monitoring (knowing what to look for), anticipating (knowing what to expect) and learning (knowing what has happened). The abilities or qualifications of the resilience components are presented in Table 7.

The associations of the underlying causes of gearbox failures and resilience characteristics are presented in Tables 8-11. By using resilience characteristics and these associations, OWT companies are able to prevent, mitigate or resolve undesired failures or conditions, e.g. as a responding characteristic of RE principles, "use golden rules" can prevent some undesirable conditions such as "unauthorized repairs/modifications", or "workaround of regulations or standard maintenance procedure by the technician". Also, "use golden rules" helps to recover from "loss of situational awareness by the technician", "Inadequate technical information of the technician about gearbox" or "time pressure".

Stage 5: First, second and third order (or level) resilience responses of the risk management system are designated and depicted in Figure 5. First order resilience is defined as Level 1 in OWT maintenance management. Resilience at this level is essentially a first order response for some disturbances and is sometimes not considered as part of resilience. Second order resilience involves not only responding, but also engages with the activities of anticipation and monitoring as a second order response (Level 2). At this level, it is often aimed at preparing for the recurrence of a similar threat/failure or opportunity for OWT maintenance. At the third level, the OWT maintenance management model begins to learn second order response experiences with appropriate and relevant feedback. At Level 3, adaptive capacity is built as an "adaptation of future requirements" component for safety management system to materialize sustained adaptability. At this level, the system's overall ability to respond is improved and built on the system's margin.

Levels of uncertainty or expected resilience magnitude can be used to obtain a resilient success model in the current study. The levels are given as follows:

First order resilience (level 1) or low resilience - High uncertainty;

Second order resilience (level 2) or medium resilience - Medium uncertainty;

Third order resilience (level 3) or high resilience - Low uncertainty. 
Stage 6: Specify uncertainties and outcomes.

The three resilience levels tend to emphasize the cornerstones of resilience activities (Level 1, responding; Level 2, monitoring and anticipating; and Level 3, learning), but the clear separation of the resilience levels is impossible due to their indeterminate boundaries in realworld applications. At all three resilience levels, technicians or teams work through maintenance operational processes to produce the required result or output, and the maintenance team/company incorporates, organises, and supports the operations which produce the outputs which carry out the organisations' safety missions. A truly resilient maintenance management system should absorb, adapt, adjust and survive at all three resilience levels. To acquire satisfactory resilience performance, an OWT organization needs to experience appropriate and relevant feedback at each resilience level. Also, the organization must critically focus on RE principles and applications to understand how to build or improve adaptive capacity of the company and how to control the mechanism for the future resilience expectations.

\subsection{How the resilience of the OWT maintenance management can be improved?}

In Tables 8-11, the underlying causes of maintenance related gearbox failures are related to the resilience components, which are identified as responding, monitoring, anticipating and learning. For each underlying cause, it was evaluated whether the resilience components can contribute to removing or mitigating the effects of the cause.

The relation between the use of resilience components and total number of causes is presented in Figure 6. Effective use of resilience elements contributes to eliminating or mitigating the effects of causes. When the Figure 6 is examined, "stop and think" tops the most effective resilience component as it removed or mitigated twenty causes. "Use Standard Operation Procedures" and "Adaptation to Future Requirements" are the other most important resilience elements to improve safety. The least effective resilience elements are seen as "Flexibility", "Having Redundancies in Place" and "Multidisciplinary (Seeing maintenance from different perspectives)". The organization can strengthen safety attitudes, knowledge, and skills by taking into account the effects of resilience principles.

Based on the analysis concrete suggestions are provided together potential improvements as follows:

\section{Resilience as responding:}


With regards to the maintenance of OWT gearbox unit, risk based maintenance operations can pursue improvements in reducing or eliminating human errors by using responding elements as described in the following:

(1) Flexibility: It is the ability of the organization to adapt to new or complex problems in a way, which maximizes its ability to solve the problems without disrupting overall functionality (Wreathall, 2006).

(2) Knowing the safety margins: The primary implication of underlying causes of gearbox failures is to account for uncertainties and risks, which can be significantly increased due to eroded or neglected safety margins without management realizing it. Safety margins refer to the limits and sequence of disassembly during the maintenance of gearbox components. In order to reduce uncertainties and increase safety, maintenance operations need to be built with adequate safety margins for technicians. This assures a high degree of safe maintenance operation with managed risk.

(3) Consult with others and think together: Thinking together as a team is the capacity to collectively solve problems, develop consistent solutions to encountered problems and overcome OWT maintenance challenges. Consulting with others helps to develop the understanding of issues, which exceed the understanding of individuals. Team work creates both new knowledge and a point of view relevant to a particular context for maintenance team members.

(4) Use golden rules: The term 'golden rule' is used as a proactive and positive quality in maintenance processes. Human errors can be reduced or eliminated successfully if the following golden rules are applied: (a) Be aware of your capacity and do not carry out maintenance tasks if you do not know how to do it (b) Be aware that there is no time pressure from the management during the maintenance operation. Do not work if time is over.

(5) Time available: Time pressure may directly constrain the cognitive skills of technicians related to creativity in the OWT work environment. Having time can be helpful for them to make powerful decisions under high uncertainty and complexity of maintenance processes.

(6) Mitigation of Cognitive biases: Mitigation of cognitive biases is the prevention and reduction of the negative effects of cognitive biases. Here are two cognitive biases as follows: (a) Technicians can have overconfidence and their subjective confidence in their judgments has greater effect than the objective accuracy of those judgments (b) 
They have an urge to finish and reach the goal right away. Overconfidence can be attenuated by requiring subjects to consider reasons that they may be wrong (Angner, 2006).

\subsubsection{Resilience as monitoring:}

Dealing with the OWT gearbox unit in risk based maintenance operations, one can pursue improvements in reducing or eliminating human errors by using monitoring elements in the following way:

(1) Checklist: Checklists could increase awareness, improve the process, and promote consistency of care. Checklists can allow structured error-capture observations using maintenance task descriptions coupled with specific practices, regulations and more general elements of safety culture and teamwork.

(2) Stop and think: Stop and think is for technicians, who will be about to start the maintenance operations. It allows technicians to make a plan on how to execute the complex maintenance operations consistently and without fault. Risk-awareness is enacted through collective or organisational practices rather than through trying to change the mindsets of individual workers (Hopkins, 2005). Risk-awareness is encouraged among the workforce, through training and learning programs, which require technicians to stop and think about risk before commencing work. There is also a need for cross-checking of important decisions to increase risk awareness and resilience in the event of failures. Cross-checking with other members of the team may reduce the chance of maintenance related errors occurring. Moreover, an understanding of the increased likelihood of human error in difficult maintenance circumstances might raise the awareness of the team, and heighten their vigilance by using the monitoring element.

(3) Multidisciplinary: Technicians must possess multidisciplinary skills in order to materialize safer and more resilient maintenance operations. Seeing different maintenance perspectives will help technicians feel more confident, enable them to be more understanding, and improve communication and relationships.

(4) Mitigation of cognitive biases: Here are two cognitive biases as follows: (a) Routine is a threat due to repeated actions during maintenance operations. (b) There is a danger of having a narrowed attention span. Effective techniques can be utilized to improve a technician's ability to stay focused and alert. A person may restore the ability to stay 
focused and alert by taking a rest, doing a different kind of activity, changing mental focus, or deliberately choosing to re-focus on the first maintenance operation.

\subsubsection{Resilience as anticipating:}

Dealing with the OWT gearbox unit in risk based maintenance operations, one can pursue improvements in reducing or eliminating human errors by using anticipating elements as provided in the following:

(1) Preparedness: Preparedness is an important resilience element in achieving goals and in avoiding and mitigating negative outcomes in the OWT maintenance operations. The OWT organization actively anticipates problems and prepares for them.

(2) Vigilance to risks: Being vigilant against potential risks and losses in maintenance operations aims to fulfil the requirements to prevent potential threats. A resilient system must be both prepared, and be prepared to be unprepared (Paries, 2011). Effective training programs to develop a constant state of vigilance to risks can be given to the employees. This training improves vigilance performance of technicians that wish to combat maintenance related hazards. Technicians taking this training is expected to become more aware of maintenance related risks.

(3) Avoid making assumptions: Employees are able to manage their condition and perform their duties to a high standard in maintenance process, avoiding making assumptions or guessing regarding the nature of failures. Making assumptions affects their ability to do their job adversely in the resilient framework. Each employee will need to be managed on a case-by-case basis depending on the nature of their duties. There is a need to be developed employees' skills, such as communication, conversation, questioning and teamwork, according to the needs of the task.

(4) Awareness and scenario thinking: Self-awareness helps technicians build resilience so they are able to bounce back from any setback in maintenance progress. The more you can foresee the things that are going to happen, the more you can prevent or prepare for the risks (Bellamy, 2015). Training for scenario and strategic planning techniques can be provided to increase awareness and scenario thinking of technicians. Technicians with distinctive options never run out of solutions. They consider worst case scenarios, take into account risks, and potential ways out during the maintenance operations.

(5) Getting little things right: Getting some little things right can make safer and resilient maintenance operations. The simple but essential things are given as follows: (a) Make 
sure you have all the right tools, equipment, technical information and maintenance guides. (b) Focus on the details of given tasks. A strong demand for safe work practices including control, reporting and transparency of the work by senior leadership can mean safer and resilient operations.

(6) Not to focus individually: This element brings people together to share intelligence, knowledge and help one another to reduce the risks. To do so, there is a need to avoid a number of stand-alone programs such as lockout, behaviour-based safety, confined space entry, job safety analysis etc. All elements of maintenance safety programs can be integrated into a single management system that is owned by line management to increase individual effectiveness and organizational capacity in the safety area.

(7) Mindfulness to minor potential problems: The minor or smallest potential things or problems can be important issues if maintenance technicians do not pay attention. It is one of the most important safety nets. It can be used mindfulness strategies to avoid critical thinking tasks. Also, technicians can prefer to disconnect from their challenges and retreat into a meditative mindset instead of rationally thinking through a career challenge or dilemma.

(8) Use systematic analysis: Maintenance operation should be carried out by the technicians in a systematic way in accordance with a planned and structured procedure. They should use standard operating procedures and checklists, which are prepared by the experts and frontline technicians, to reduce risks. They schedule their duties and log of control for recommendations and report the obtained maintenance activities.

\subsubsection{Resilience as learning:}

Dealing with the OWT gearbox unit in risk based maintenance operations, one can pursue improvements in reducing or eliminating human errors by using learning elements in the following:

(1) Use captured useful feedbacks: Tight feedback loops between team members allow them to recover or mitigate failures. Having a continuous feedback loop provides an effective early detection system for technicians. Changes in employee behaviour and the associated risks are identified quickly, enabling remedial action to be taken.

(2) Having redundancies in place: The operational safety and availability of the OWT plant can be improved by having redundancies for OWT. Redundancies are significant contributors to the plant's sustainable energy productiveness. 
(3) Learning culture: A learning culture is a collection of organizational values, practices and processes. These cultural values encourage employees and organizations to develop knowledge and competence. Employees are encouraged to ask questions, share successes and lessons learned, and propagate and fertilize ideas in a learning culture. A learning culture in an organization increases efficiency, productivity and employee satisfaction.

(4) Adaptation to future requirements: The organization and technicians should be capable of adaptation to future requirements. They identify technical, human and organizational risks early in the maintenance operation cycle while they still have time to do something about them.

(5) Use standard operating procedures (SOPS): An important aspect of resilient maintenance operations is to work according to unambiguous, fit for purpose, Standard Operating Procedures (SOPs). The whole maintenance process should be described by a continuous series of SOPs. SOP is a document, which describes the regularly repeated steps and relevant to the quality of the maintenance operation. The purpose of a SOP is to carry out the operations correctly and always in the same and resilient manner. A SOP should be available at the place where the OWT gearbox maintenance work is carried out. The procedures are used for operating instruments, apparatus and other equipment, and carrying out safety precautions. SOPs are highly efficient only if all the steps are executed without skipping any of the steps or performing workaround. In order to enhance the successes of SOPs, checklists are effective approach to compliment SOPs.

(6) Effective education, training with simulation studies and exercises: With the OWT gearbox system maintenance the human has a critical role in ensuring the safety of the operations. Human decisions can only be understood in the context in which they are taken. Competency in every role is essential to sustain reliable and safe maintenance operations. With effective education and training applications, the OWT organization empowers individuals and devolves responsibility, recognising experience and expertise. Training is relevant and provides the right knowledge and skills for the maintenance personnel.

(7) Do not confuse luck and success: There is a danger of being attracted to success. Sometimes success is just luck and not a result of being resilient (RSC, 2015). 


\subsection{Limitations of the Proposed Resilient Maintenance Management Model}

Many of the resilient elements presented and applied here could be viewed as good risk management practice to mitigate failures across all OWT maintenance operations, and not limited to the use of the narrow context of safety-critical operations. Creating resilience in safety critical maintenance operations may create additional costs for companies as it will generate higher reliability by encouraging redundancy, experience, learning, effective training and increased quality of maintenance. However, this will be easily compensated by producing more electricity due to the increased availability.

Additionally, as organizations still lack the validation process, high resilient maintenance management and definition of high reliability characteristics and resilient features of Offshore Wind Farms have to be linked objectively to improve organizational or safety performance. Organisations must improve how they learn from experience and collaborate with others to address the risks in maintenance operations and create a safety culture by questioning and challenging in the organisation.

\section{Conclusion}

In this study, one of the challenges is to move the cornerstones of RE from the research domain into OWT maintenance and operation. RE principles can be seen as an important factor for OWT risk management to handle the situations related to the human/organizational factors where strict adherence to emergency maintenance procedures would not guarantee successful risk management. Therefore, the ability to learn, anticipate, monitor and respond to emergency procedures of the OWT maintenance was considered as an important resilience mechanism. The integration of RE principles by considering human factors, organizational procedures and processes of OWT management increases reliability and adaptability of OWT maintenance. The overall contribution of the paper is to raise awareness of RE and its principles, and to bring $\mathrm{RE}$ and its principles into the offshore wind domain to recover, prevent or mitigate incidents/accidents. This will also contribute to all organizations, companies or personnel involved in OWT maintenance operations in order to integrate or be equipped with resilient systems or tools in their work environment.

Complexity of the Offshore Wind Turbines operations requires to assure the safe operation and maintenance of these systems. National Offshore Wind Energy Authorities must consider to develop a safety program and this program supports the continued evolution of a proactive 
strategy to improve safety performance which is also linked to availability to produce more electricity. The foundation of this proactive safety strategy is based on the implementation of a Safety Management System (SMS) that systematically addresses safety risks. An approved training organization exposing to safety risks related to maintenance operations may control the implementation of SMS. The organization strengthen safety attitudes, knowledge, and skills of OWT technicians by taking into account RE principles. This should reduce greatly safety risks, maintenance and human error costs.

Resilience has been an important and popular concept over the last few years. However, in order to increase its application in engineering issues, there is a need to incorporate the RE's promising feature of sustained adaptability to a dynamic environment. The future work of this study will focus on the demonstration of its sustained adaptability to address OWT maintenance and operational safety.

\section{Acknowledgements}

This work was carried out during the corresponding author's academic visit to the University of Strathclyde. The authors would like to thank staff members of the Naval Architecture and Marine Engineering Department at the University of Strathclyde for their help and support. The authors gratefully acknowledge the Scientific and Technological Research Council of Turkey (TUBITAK) for the financial support of the International Postdoctoral Research Scholarship Programme, 2219. 


\section{References}

Allenby, B., Fink, J., 2005. Toward inherently secure and resilient societies. Science, 309 (5737), 1034-1036.

Angner, E., 2006. Economists as experts: Overconfidence in theory and practice. Journal of Economic Methodology, 13 (1), 1-24.

ATSB, 2001. Australian Transport Safety Bureau (ATSB) Survey of Licensed Aircraft Maintenance Engineers in Australia. Department of Transport and Regional Service, Canberra, Australia.

Bellamy, L.J., 2015. Bowtie resilience project: Success in the face of uncertainty. Bowtie Methodology for Risk Assessment \& Management in Aviation, Aloft Aviation Consulting \& Irish Aviation Authority, Dublin.

Bergström, J., Van Winsenb, R., Henriqsonc, E., 2015. On the rationale of resilience in the domain of safety: A literature review. Reliability Engineering \& System Safety, 141, 131-141.

CWIF, 2018. Wind Turbine Accident Data. Caithness Windfarm Information Forum (CWIF). Available from: http://www.caithnesswindfarms.co.uk/AccidentStatistics.htm (Accessed 9 February 2018).

Dalgic, Y., 2015, 'Development of Offshore Wind Operational Expenditure Model and Investigation of Optimum Operation and Maintenance Fleet', $\mathrm{PhD}$ thesis, University of Strathclyde

Dalgic, Y., Lazakis, I. \& Turan, O., 2015ª Investigation of Optimum Crew Transfer Vessel Fleet for Offshore Wind Farm Maintenance Operations. Wind Engineering, 39, 31-52.

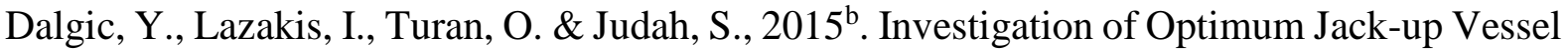
Chartering Strategy for Offshore Wind Farm O\&M Activities. Ocean Engineering, 95, 106115.

Dekker, S., 2014. The field Guide to Understanding 'Human Error'. Third Edition, CRC Press, Taylor\&Francis Group, London.

Emanuelsson, H.-E., 2011. Basic maintenance techniques for wind energy technicians. Heetech Consulting, AB.

Eurocontrol, 2009. A white paper on resilience engineering for ATM, cooperative network design. European Organisation for the Safety of Air Navigation (EUROCONTROL), 1-14. 
EWEA, 2009. The economics of wind energy. European Offshore Energy Association (EWEA), Brussels.

EWEA, 2015. The European offshore wind industry - key trends and statistics 1st half 2015. European Offshore Energy Association (EWEA), Brussels.

Fairbanks, R.J., Wears, R.L., Woods. D.D., Hollnagel, E., Plsek, P.E., Cook, R.I., 2014. Resilience and resilience engineering in healthcare. Joint Commission Journal on Quality and Patient Safety, 40 (8), 376-383.

Favaro, F.M., Saleh, J.H., 2014. Observability-in-Depth: An Essential Complement to the Defense-in-Depth Safety Strategy in The Nuclear Industry. Nuclear Engineering and Technology, 46(6), 803-816.

GCube, 2013. Top 5 US Wind Energy Insurance Claims Report. Available from: http://www.gcube-insurance.com/en/top-5-wind-energy-claims (Accessed 6 April 2015).

Hobbs, A., Williamson, A., 2002. Unsafe acts and unsafe outcomes in aircraft maintenance. Ergonomics, 45, 866-882.

Hollnagel, E., 1990. The Phenotype of Erroneous Actions: Implications for HCI Design. In Weir, G. \& Alty, J. (Eds) Human - Computer Interaction and Complex Systems. London Academic Press.

Hollnagel, E., 1998. Cognitive Reliability and Error Analysis Method (CREAM). New York: Elsevier Science Inc.

Hollnagel, 2004. Barriers and Accident Prevention. Ashgate Publishing, Hampshire, UK.

Hollnagel, E., 2006. Resilience - the challenge of the unstable. In E. Hollnagel, D. Woods, \& N. Leveson (Eds.). Resilience engineering: Concepts and precepts. Aldershot, UK: Ashgate Publishing.

Hollnagel, J., 2011. Resilience Engineering in Practice: A Guidebook. Hollnagel, J. Paries, D., Woods, D., Wreathall, J. (Eds.), 193-198, Aldershot, UK: Ashgate.

Hollnagel, E., Rigaud, E. (Eds.), 2006. Proceedings of the second Resilience Engineering Symposium, Juan-les-Pins, France.

Homeland Security, National Infrastructure Protection Plan (NIPP), Washington, DC, 2009

Homeland Security, 2013. Partnering for Critical Infrastructure Security and Resilience. NIPP, USA. 
Hopkins, A., 2005. Safety, culture and risk. Sydney: CCH Australia.

Hourtolou, D., Salvi, O, 2003. ARAMIS Project: Development of an Integrated Accidental Risk Assessment Methodology for Industries in the Framework of SEVESO II Directive, Bedford, T. and Gelder, P.H.A.J.M. van. Safety and Reliability ESREL 2003, 829-836.

ISO 17776, 2000. Petroleum and natural gas industries - Offshore production installations Guidelines on tools and techniques for hazard identification and risk assessment. BS EN ISO. Jackson, S., 2010. Architecting Resilient Systems, Accident Avoidance and Survival and Recovery from Disruptions. New Jersey: John Wiley and Sons, Inc.

Jackson, S., Ferris, T., 2013. Resilience principles for engineered systems. Systems Engineering, 16(2), 152-164.

Miao, X., Banister, D., 2012. Coping with Natural Disasters through Resilience. School of Management, Harbin Institute of Technology, Transport Studies Unit, University of Oxford. Working Paper No: 1059.

Moench, M., 2009. Adapting to climate change and the risks associated with other natural hazards: methods for moving from concepts to action. Earthscan Reader on Adaptation to Climate Change, 249-280, Earthscan, London.

Paries, D., 2011. Resilience Engineering in Practice: A Guidebook. Hollnagel, J. Paries, D., Woods, D., Wreathall, J. (Eds.), 193-198, Aldershot, UK: Ashgate

Pennie, D.J., Brook-Carter, N., Gibson, W.H., 2007. Human factors guidance for maintenance. The Royal Institution of Naval Architects, Human Factors in Ship Design. In: Safety and Operation Conference, London, UK, March.

PPD-21, 2013. White House National Security Strategy report, White House, USA.

Raftery, M., 2012. the dark side of "green": wind turbine accidents, injuries and fatalities raise serious safety concerns. Available from: http://www.eastcountymagazine.org/dark-side$\% \mathrm{E} 2 \% 80 \% 9 \mathrm{Cgreen} \% \mathrm{E} 2 \% 80 \% 9 \mathrm{D}$-wind-turbine-accidents-injuries-and-fatalities-raiseserious-safety-concerns (Accessed 14 May 2015).

Rasmussen, J., 1979. Notes on Human Error Analysis and Prediction. In Synthesis and Analysis Methods for Safety and Reliability Studies, ed. G. Apostolakis and G. Volta. Plenum Press. London. 
Rasmussen, J,, 1987. The Definition of Human Error and a Taxonomy for Technical Change. In Rasmussen, J., Duncan, K. \& Leplat, J. (eds.) New Technology and Human Error. London, Wiley.

Reason, J., 1990. Human Error. Cambridge University Press, Cambridge.

Reason, J., 1998. Achieving a safe culture: Theory and practice. Work \& Stress: An International Journal of Work, Health \& Organisations, 12(3).

Resilience Engineering Association, 2015. Available from: http://www.resilience-engineeringassociation.org (Accessed 26 February 2015).

Righi, A.W., Saurin, T.A., Wachs, P. 2015. A systematic literature review of resilience engineering: Research areas and a research agenda proposal. Reliability Engineering \& System Safety, 141, 142-152.

Robinson, C.M.E., Paramasivam, E.S., Taylor, E.A., Morrison, A.J.T., Sanderson, E.D., 2013. Study and development of a methodology for the estimation of the risk and harm to persons from wind turbines. HSE Books, Crown copyright, UK.

RSC, 2015. Success in the face of Uncertainty: Human Resilience and the accident Risk Bowtie. Resilience Engineering Consortium, Rev 12, Final Report.

Sklet, S., 2004. Comparison of some selected methods for accident investigation. Journal of Hazardous Materials, 111, 29-37.

Svenson, O., 1991. The accident evolution and barrier function (AEB) model applied to incident analysis in the processing industries. Risk Analysis, 11, 499-507.

Swain, A.D., 1982. Modelling of human performance in complex systems with emphasis on nuclear power plant operations and probabilistic risk assessment. Ergonomics, 25(6), 449.

Swain, A.D., Guttmann, H.E., 1983. Handbook on Human Reliability Analysis with Emphasis on Nuclear Power Plant Applications. NUREG/CR1278, USNRC.

Trbojevic, V.M., 2008. Optimising Hazard Management by Workforce Engagement and Supervision. Prepared by Risk Support Limited for the Health and Safety Executive, RR637, HSE Research Report, London.

Wears, R.L., Morrison, J.B., 2013. Levels of Resilience: Moving from Resilience to Resilience Engineering. Proceedings of the $5^{\text {th }}$ International Symposium on Resilience Engineering (in review), Utrecht, the Netherlands. 
Windstats Reports, Vols. 19, 22, and 25, Q1 - Q4 in 2006, 2009, and 2012.

Woods, D. D., 2006. Essential characteristics of resilience. In E. Hollnagel, D. D. Woods, \& N. Leveson (Eds.), Resilience engineering: Concepts and precepts, 21-34, Aldershot, UK: Ashgate.

Woods, D.D., 2003. Creating foresight: how resilience engineering can transform NASA's approach to risky decision making. Testimony on the future of NASA for committee on commerce, science and transportation.

Woods, D.D., Branlat, M., 2011. Basic patterns in how adaptive systems fail. Resilience Engineering in Practice: A Guidebook. Hollnagel, J. Paries, D., Woods, D., Wreathall, J. (Eds.), 127-143, Aldershot, UK: Ashgate.

Woods, D., Wreathall, J., 2003. Managing risk proactively: the emergence of resilience engineering. Institute for Ergonomics: The Ohio State University.

Wreathall, J., 2006. Properties of resilient organizations: an initial view. In E. Hollnagel, D. D. Woods, \& N. Leveson (Eds.), Resilience engineering: Concepts and precepts, 275-285, Aldershot, UK: Ashgate.

WWEA, 2015. WWEA. New Record in Worldwide Wind Installations. Quarterly Bulletin: Wind Energy around the World, Issue 1. 
Wind Turbine Accidents

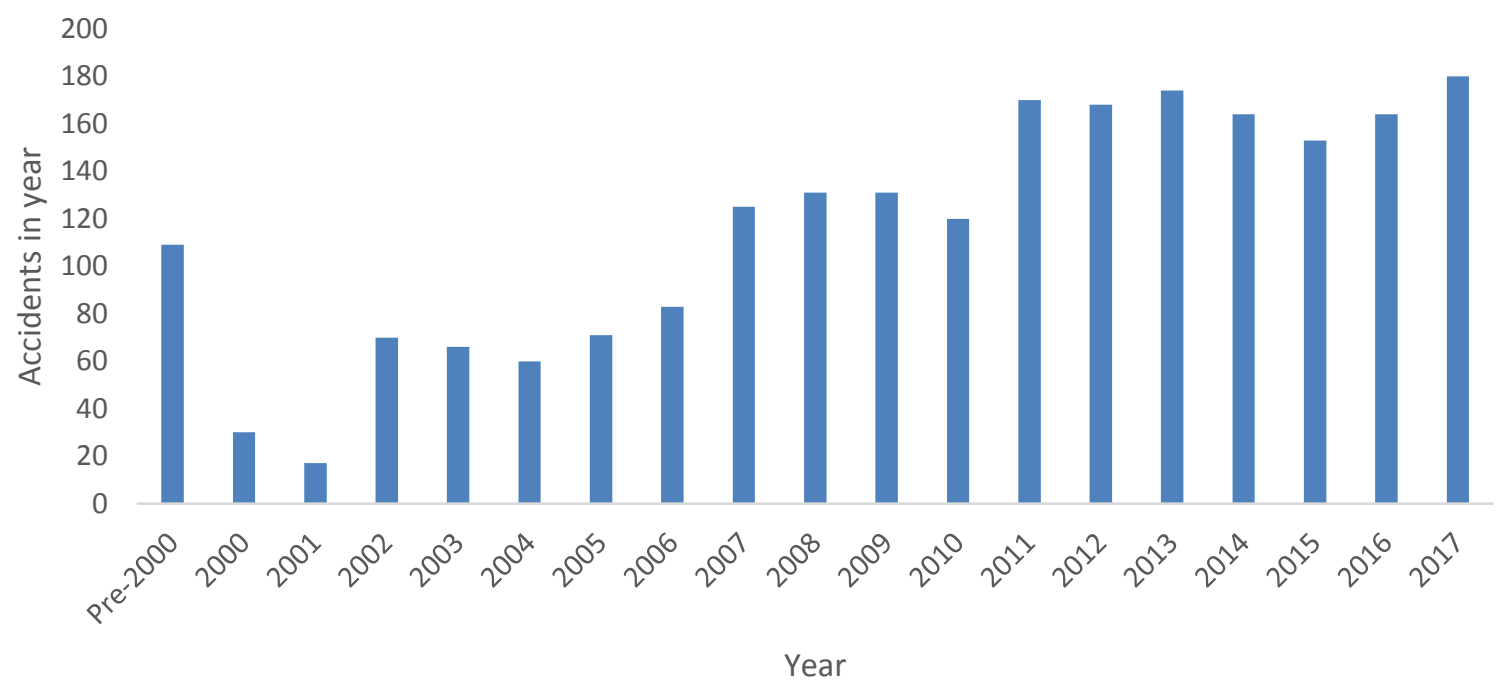

Figure 1 Wind Turbine Accidents (CWIF 2018). 


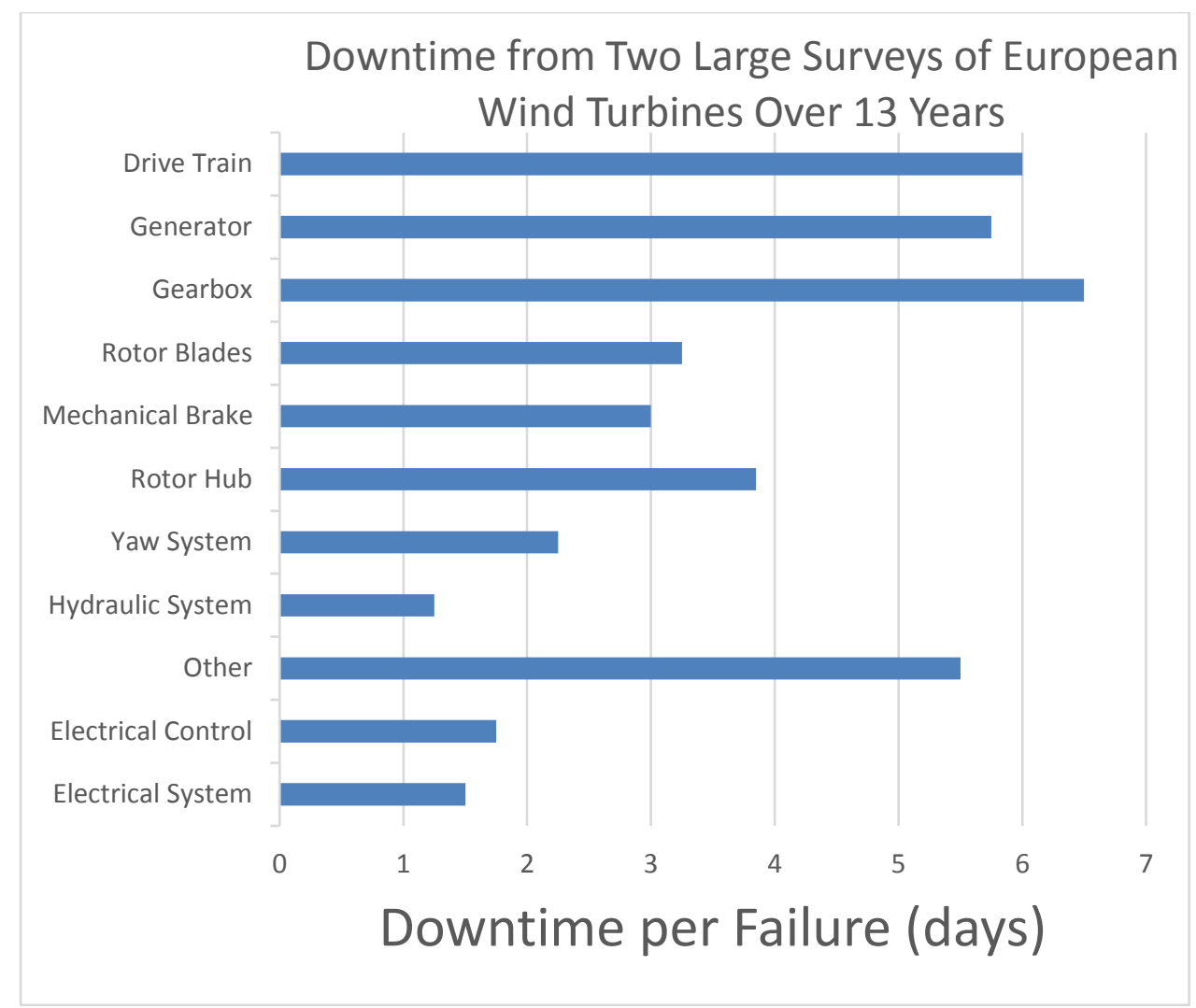

Figure 2 Downtime Failures (Windstats Reports, 2009) 


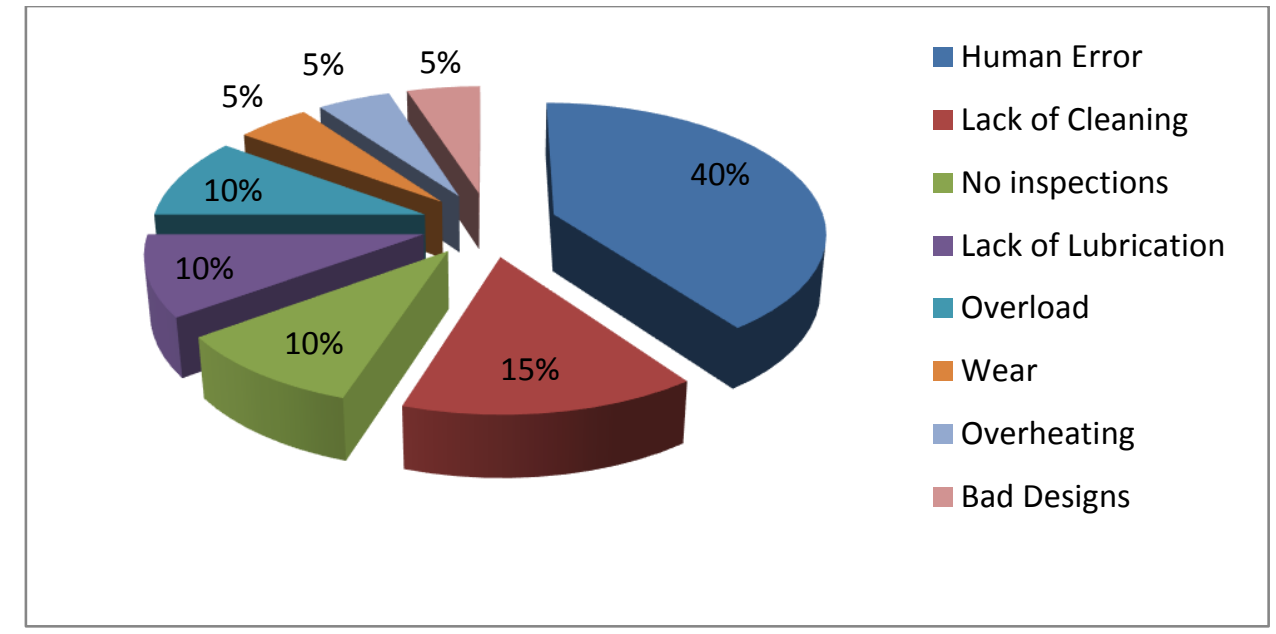

Figure 3 Failures due to Wind Turbine Maintenance (Emanuelsson, 2011) 


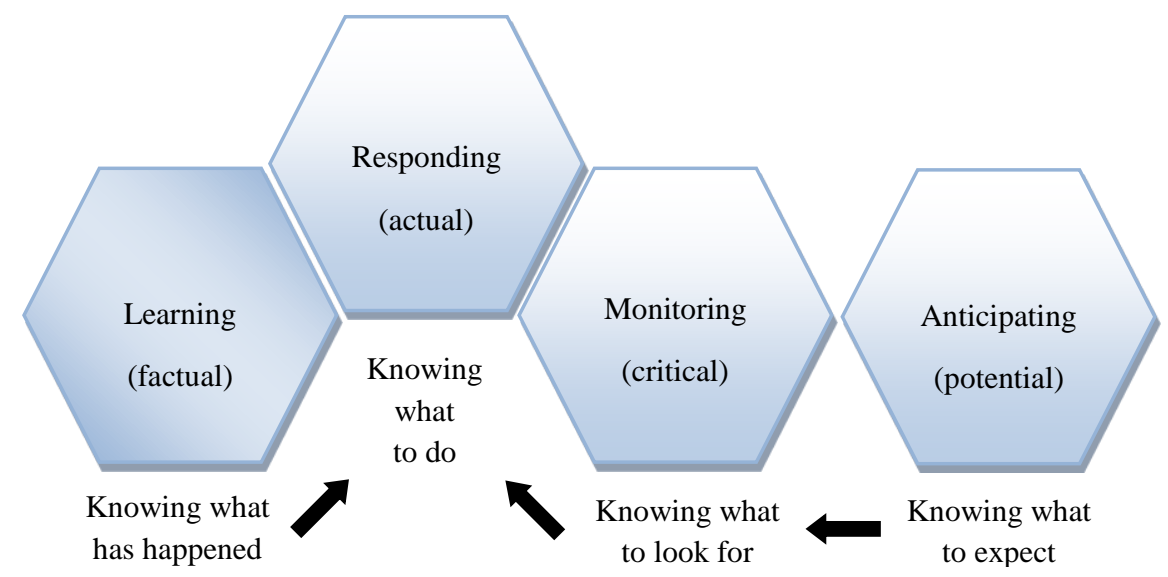

Figure 4 The four cornerstones of resilience (Hollnagel, 2011). 


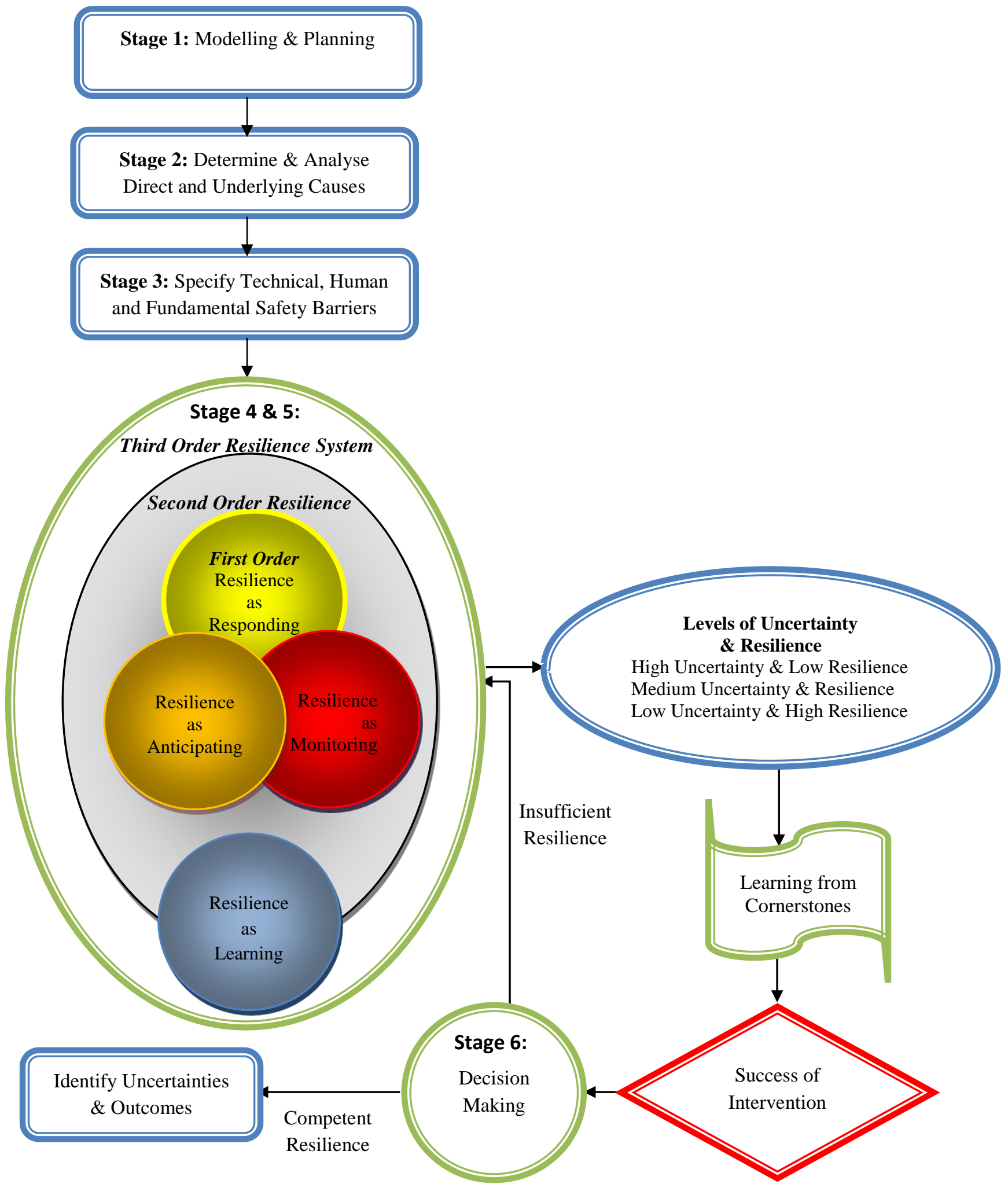

Figure 5 Levels of Resilience for OWT Risk Based Maintenance Management 
Do not confuse luck and success Effective education, training with simulation studies and exercises Use standard operating procedures (SOPs)

Adaptation to future requirements Learning culture Having redundancies in place Use captured useful feedbacks Use systematic analysis Mindfulness to minor potential problems Not to focus individually Getting little things right Awareness and Scenario thinking

Avoid making assumptions Vigilance to risks Preparedness

Mitigation of cognitive biases (routine, narrowed attention) Multidisciplinary (Seeing maintenance from different perspectives) Stop and think (cross check) Checklist Time available Use golden rules Consult with others and think together Knowing the safety margins Flexibility

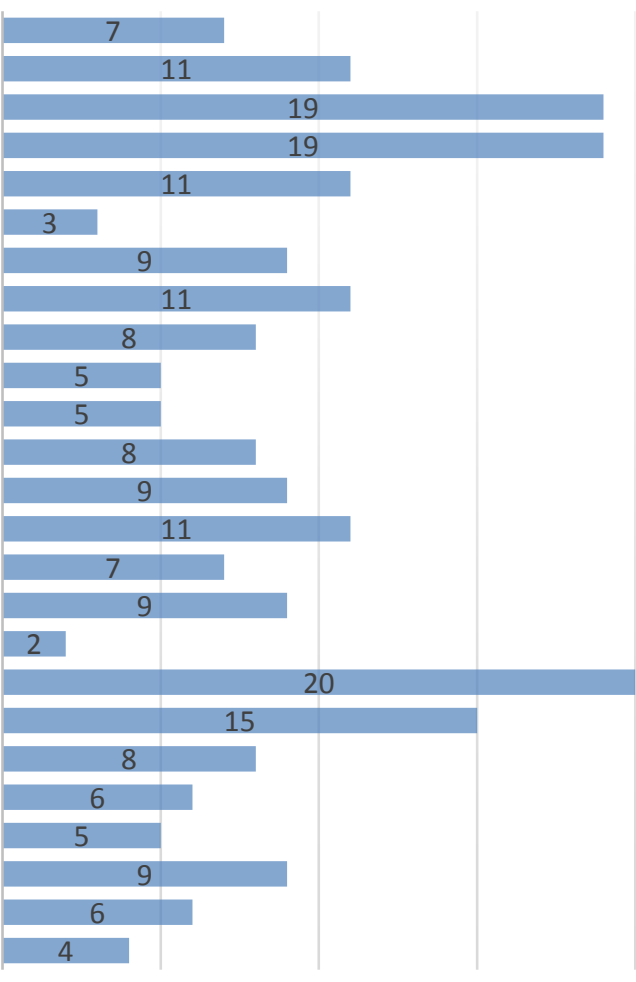

0

Figure 6. The relation between Resilience Elements and Causes 
Table 1 Potential Main Results of an Offshore Wind Turbine Hazard

\begin{tabular}{ll}
\hline No. & Results \\
\hline 1 & Blade Failure \\
2 & Rotor (Hub) Failure \\
3 & Bearing and Shaft Failure \\
4 & Main Shaft Gearbox Coupling Failure \\
5 & Gearbox Failure \\
6 & Generator Failure \\
7 & Tower and Foundation Failure \\
8 & Power Electronics and Electric Controls Failure \\
9 & Yaw and Pitch Control Failure \\
10 & Meteorological Measurement System Failure \\
11 & Grid Connection Failure \\
\hline
\end{tabular}


Table 2 Main Direct Causes of Maintenance Related Gearbox Failures

\begin{tabular}{ll}
\hline No. & Cause of Failure \\
\hline 1 & Shaft gearbox coupling failure \\
2 & Gearbox generator coupling failure \\
3 & Thermal instability \\
4 & Torsional and lateral vibrations \\
5 & Unexpected load \\
6 & Lubrication failure \\
7 & Foreign object in gearbox \\
8 & Misalignments \\
9 & Manufacturing error \\
10 & Material degradation \\
11 & Erosion induced failure \\
14 & Fatigue \\
15 & Gear eccentricity \\
16 & Corrosion induced failure \\
17 & External factors (weather) \\
18 & Human error \\
\hline
\end{tabular}


Table 3 Main Causes of Organizational Risk Factors for OWT Maintenance and Operation

\begin{tabular}{ll}
\hline No. & Cause of Failure \\
\hline 1 & Ineffective and Deficient Maintenance Management Program \\
2 & Inadequate Risk Inventory and Management \\
3 & Disability to Generate Meaningful Management Reports \\
4 & Insufficient Identification of Reliability Problems \\
5 & Incapable of evaluation of Maintenance Effectiveness \\
6 & Inadequacy to Rapid Access to Maintenance History \\
7 & Inadequacy of Well Trained Maintenance Staff \\
8 & Inadequate Current Technical Manuals and Documentation \\
9 & Deficiencies about Building up Maintenance and Test Procedures \\
10 & Undetermined Maintenance Requirements \\
1 & Undetermined Skill Level Personnel Requirements \\
12 & Unplanned Operation and Maintenance Training Requirements \\
13 & Unplanned Operation and Maintenance Staff Requirements \\
14 & General Obligations of Employees \\
15 & Information \& Knowledge Deficiencies \\
16 & Inadequate Audit \& Review \\
17 & Insufficient Monitoring \\
18 & Incapable of Workload Management \\
19 & Inactive Coordination \& Communication \\
20 & Disability to Manage Uncertainties \\
21 & Insufficient Organizational \& Safety Culture \\
\hline
\end{tabular}


Table 4 Underlying Causes of Maintenance Related Gearbox Failure

\begin{tabular}{|c|c|c|}
\hline No. & Cause of Failure & Failure Type \\
\hline 1 & Excessive/lower/wrong lubrication or greasing & $\begin{array}{l}\text { Skill-based error / Judgment and } \\
\text { decision making error }\end{array}$ \\
\hline 2 & $\begin{array}{l}\text { Inadequate technical information of the technician } \\
\text { about gearbox }\end{array}$ & $\begin{array}{l}\text { Skill-based error/ Judgment and } \\
\text { decision making error / } \\
\text { Organizational influences }\end{array}$ \\
\hline 3 & Improper cleaning during maintenance & Adverse mental state / Violation \\
\hline 4 & Incorrect installation & $\begin{array}{l}\text { Skill-based error / Judgment and } \\
\text { decision making error }\end{array}$ \\
\hline 5 & $\begin{array}{l}\text { Ignoring alignment check suggestions (e.g. } \\
\text { excessive backlash of teeth) }\end{array}$ & $\begin{array}{l}\text { Skill-based error / Judgment and } \\
\text { decision making error }\end{array}$ \\
\hline 6 & $\begin{array}{l}\text { Forgetting open panels, loose components, } \\
\text { unfixed covers (e.g. bolts) }\end{array}$ & Routine violation \\
\hline 7 & Gearbox bearing calibration failure & Adverse mental state \\
\hline 8 & Unauthorized repairs/modifications & $\begin{array}{l}\text { Judgment and decision making } \\
\text { error }\end{array}$ \\
\hline 9 & $\begin{array}{l}\text { Improper torque application during fitting of } \\
\text { couplings, gearbox components, etc. }\end{array}$ & $\begin{array}{l}\text { Skill-based error / Judgment and } \\
\text { decision making error }\end{array}$ \\
\hline 10 & Operating beyond lubricant life & $\begin{array}{l}\text { Judgment and decision making } \\
\text { error / Violation }\end{array}$ \\
\hline 11 & Careless use of measurement devices & Skill-based error \\
\hline 12 & Leave foreign object in gearbox (e.g. debris) & Adverse mental state \\
\hline 13 & Omitted checklist item & Skill-based error / Violation \\
\hline 14 & Improper inspection & $\begin{array}{l}\text { Skill-based error / Judgment and } \\
\text { decision making error }\end{array}$ \\
\hline 15 & Use of defected parts & Routine violation \\
\hline 16 & Inadequate organizational guidance & Oversight \\
\hline 17 & Poor decision by the technician & $\begin{array}{l}\text { Skill-based error / Judgment and } \\
\text { decision making error }\end{array}$ \\
\hline 18 & Loss of situational awareness by the technician & $\begin{array}{l}\text { Judgment and decision making } \\
\text { error / Adverse mental states }\end{array}$ \\
\hline 19 & Procedural mistakes by the technician & $\begin{array}{l}\text { Judgment and decision making } \\
\text { error }\end{array}$ \\
\hline 20 & $\begin{array}{l}\text { Bending of regulations or standard maintenance } \\
\text { procedure by the technician }\end{array}$ & Routine violation \\
\hline 21 & Organizational failure to enforce regulations & Oversight \\
\hline 22 & $\begin{array}{l}\text { Organizational failure to track technician's } \\
\text { performance }\end{array}$ & Oversight \\
\hline 23 & Poor planning of organization & Oversight \\
\hline 24 & $\begin{array}{l}\text { Supervisory failure to inspect work done or other } \\
\text { technician's duties }\end{array}$ & Supervisory violation \\
\hline 25 & $\begin{array}{l}\text { Omitting a step or more in the maintenance task } \\
\text { sequence }\end{array}$ & Skill-based error \\
\hline 26 & $\begin{array}{l}\text { Use of unauthorized materials/parts or } \\
\text { unauthorized repairs/modifications }\end{array}$ & Routine violation \\
\hline 27 & Time pressure & Organizational process violation \\
\hline
\end{tabular}


Table 5 Preventive maintenance and routine periodic tasks and inspections for wind turbines

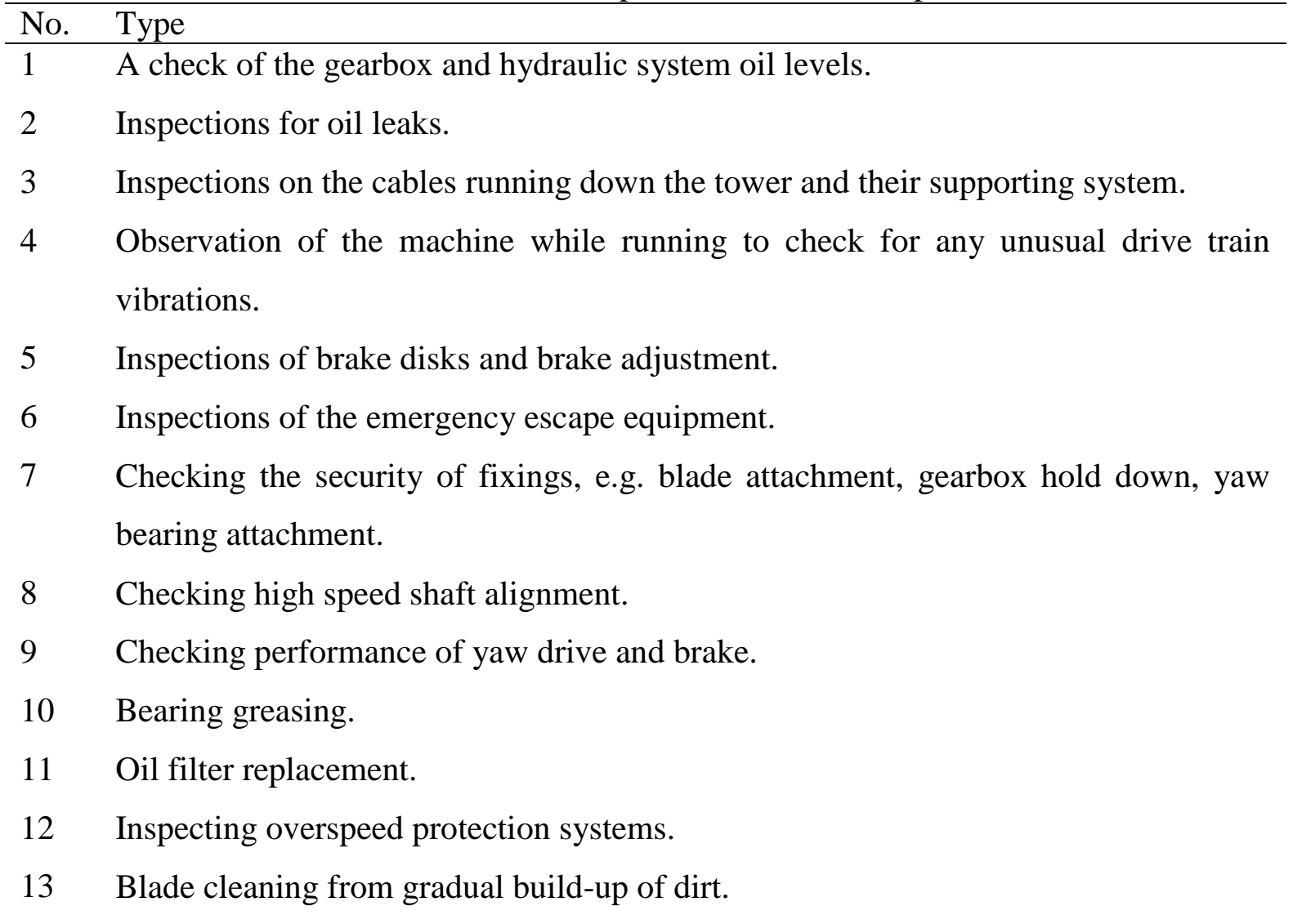


Table 6 Barriers to Prevent Offshore Wind Turbine Gearbox Failures

\begin{tabular}{|c|c|}
\hline Technical barriers & $\begin{array}{l}\text { Construction / commissioning / review } \\
\text { Operational review (best practice) } \\
\text { Procedural review }\end{array}$ \\
\hline $\begin{array}{l}\text { Human / } \\
\text { Organizational } \\
\text { barriers }\end{array}$ & $\begin{array}{l}\text { Effective supervision } \\
\text { Monitoring, detection and testing } \\
\text { Effective training programs } \\
\text { Increase training - rules and procedures } \\
\text { Increase training - hazards and risks } \\
\text { Gantt Chart / Checklists } \\
\text { Effective cleaning program }\end{array}$ \\
\hline $\begin{array}{c}\text { Fundamental } \\
\text { barriers }\end{array}$ & $\begin{array}{l}\text { Procedural review } \\
\text { Operational review } \\
\text { Design review } \\
\text { Corporate audit / Third party verification } \\
\text { Competence assurance } \\
\text { Procedural control }\end{array}$ \\
\hline
\end{tabular}


Table 7 Characteristics of Principles of Resilience Engineering

\begin{tabular}{llll}
\hline \multicolumn{1}{c}{ Responding } & Monitoring & Anticipating & Learning \\
\hline Flexibility & Checklist & Preparedness & Use captured useful feedback \\
Knowing the safety margins & Stop and think & Vigilance to risks & Having redundancies in place \\
Consult with others and think & Multidisciplinary (Seeing & Avoid making assumptions & A learning culture \\
together & maintenance from different & Awareness and scenario thinking & Adaptation to future requirements \\
Use golden rules & perspectives) & Getting little things right & Use standard operating \\
Time available & Mitigation of cognitive biases & Not to focus individually & procedures (SOPs) \\
Mitigation of cognitive biases & (routine, narrowed attention) & Mindfulness to minor potential & Effective education, training with \\
(Overconfidence, having an urge & Vigilance to risks & problems & simulation studies and exercises \\
to reach a goal). & & Use systematic analysis & Do not confuse luck and success
\end{tabular}


Table 6 Barriers to Prevent Offshore Wind Turbine Gearbox Failures

\begin{tabular}{|c|c|}
\hline Technical barriers & $\begin{array}{l}\text { Construction / commissioning / review } \\
\text { Operational review (best practice) } \\
\text { Procedural review }\end{array}$ \\
\hline $\begin{array}{l}\text { Human / } \\
\text { Organizational } \\
\text { barriers }\end{array}$ & $\begin{array}{l}\text { Effective supervision } \\
\text { Monitoring, detection and testing } \\
\text { Effective training programs } \\
\text { Increase training - rules and procedures } \\
\text { Increase training - hazards and risks } \\
\text { Gantt Chart / Checklists } \\
\text { Effective cleaning program }\end{array}$ \\
\hline $\begin{array}{c}\text { Fundamental } \\
\text { barriers }\end{array}$ & $\begin{array}{l}\text { Procedural review } \\
\text { Operational review } \\
\text { Design review } \\
\text { Corporate audit / Third party verification } \\
\text { Competence assurance } \\
\text { Procedural control }\end{array}$ \\
\hline
\end{tabular}


Table 7 Characteristics of Principles of Resilience Engineering

\begin{tabular}{llll}
\hline \multicolumn{1}{c}{ Responding } & Monitoring & Anticipating & Learning \\
\hline Flexibility & Checklist & Preparedness & Use captured useful feedback \\
Knowing the safety margins & Stop and think & Vigilance to risks & Having redundancies in place \\
Consult with others and think & Multidisciplinary (Seeing & Avoid making assumptions & A learning culture \\
together & maintenance from different & Awareness and scenario thinking & Adaptation to future requirements \\
Use golden rules & perspectives) & Getting little things right & Use standard operating \\
Time available & Mitigation of cognitive biases & Not to focus individually & procedures (SOPs) \\
Mitigation of cognitive biases & (routine, narrowed attention) & Mindfulness to minor potential & Effective education, training with \\
(Overconfidence, having an urge & Vigilance to risks & problems & simulation studies and exercises \\
to reach a goal). & & Use systematic analysis & Do not confuse luck and success
\end{tabular}


Table 8 Association of Resilience as Responding Component with OWT Risk Based Maintenance Management Systems

\begin{tabular}{|c|c|c|c|c|c|c|}
\hline \multirow[b]{2}{*}{ Cause of Failures } & \multicolumn{6}{|c|}{ RESILIENCE AS RESPONDING } \\
\hline & Flexibility & $\begin{array}{l}\text { Knowing the safety } \\
\text { margins }\end{array}$ & $\begin{array}{l}\text { Consult with others } \\
\text { and think together }\end{array}$ & Use golden rules & Time available & $\begin{array}{l}\text { Mitigation of cognitive biases } \\
\text { (overconfidence, having an urge to } \\
\text { reach the goal) }\end{array}$ \\
\hline Excessive/lower/wrong lubrication or greasing & & $\bullet$ & $\bullet$ & & & \\
\hline $\begin{array}{l}\text { Inadequate technical information of the technician about } \\
\text { gearbox }\end{array}$ & & & & $\bullet$ & & \\
\hline Improper cleaning during maintenance & & & $\bullet$ & & $\bullet$ & \\
\hline Incorrect installation & & & $\bullet$ & & & \\
\hline Ignoring alignment check suggestions & & & & & $\bullet$ & $\bullet$ \\
\hline $\begin{array}{l}\text { Forgetting open panels, loose components, unfixed covers } \\
\text { (e.g. bolts) }\end{array}$ & & & $\bullet$ & & & $\bullet$ \\
\hline \multicolumn{7}{|l|}{ Gearbox bearing calibration failure } \\
\hline Unauthorized repairs/modifications & & & & $\bullet$ & & $\bullet$ \\
\hline $\begin{array}{l}\text { Improper torque application during fitting of couplings, } \\
\text { gearbox components, etc. }\end{array}$ & & $\bullet$ & & & & \\
\hline Operating beyond lubricant life & & $\bullet$ & & & & \\
\hline \multicolumn{7}{|l|}{ Careless use of measurement devices } \\
\hline Leave foreign object in gearbox (e.g. debris) & & & & & & $\bullet$ \\
\hline Omitted checklist item & & & & & $\bullet$ & $\bullet$ \\
\hline Improper inspection & & & $\bullet$ & & & \\
\hline Use of defected parts & & $\bullet$ & & & & \\
\hline \multicolumn{7}{|l|}{ Inadequate organizational guidance } \\
\hline Poor decision by the technician & & & $\bullet$ & & & \\
\hline Loss of situational awareness by the technician & & & $\bullet$ & $\bullet$ & & \\
\hline Procedural mistakes by the technician & & & - & & & \\
\hline $\begin{array}{l}\text { Workaround of regulations or standard maintenance } \\
\text { procedure by the technician }\end{array}$ & & $\bullet$ & & $\bullet$ & $\bullet$ & $\bullet$ \\
\hline Organizational failure to enforce regulations & $\bullet$ & & & & & \\
\hline \multicolumn{7}{|l|}{ Organizational failure to track technician's performance } \\
\hline Poor planning of organization & $\bullet$ & & & & & \\
\hline $\begin{array}{l}\text { Supervisory failure to inspect work done or other } \\
\text { technician's duties }\end{array}$ & $\bullet$ & & & & & \\
\hline Omitting a step or more in the maintenance task sequence & & & $\bullet$ & & - & - \\
\hline Use of unauthorized materials/parts & & $\bullet$ & & & & \\
\hline Time pressure & • & & & - & - & - \\
\hline
\end{tabular}


Table 9 Association of Resilience as Monitoring Component with OWT Risk Based Maintenance Management Systems

\begin{tabular}{|c|c|c|c|c|}
\hline \multirow[b]{2}{*}{ Cause of Failures } & \multicolumn{4}{|c|}{ RESILIENCE AS MONITORING } \\
\hline & Checklist & Stop and think (cross check) & $\begin{array}{l}\text { Multidisciplinary (Seeing maintenance } \\
\text { from different perspectives) }\end{array}$ & $\begin{array}{c}\text { Mitigation of cognitive biases } \\
\text { (routine, narrowed attention) }\end{array}$ \\
\hline Excessive/lower/wrong lubrication or greasing & $\bullet$ & $\bullet$ & & \\
\hline $\begin{array}{l}\text { Inadequate technical information of the technician about } \\
\text { gearbox }\end{array}$ & & & $\bullet$ & \\
\hline Improper cleaning during maintenance & & $\bullet$ & & $\bullet$ \\
\hline Incorrect installation & $\bullet$ & $\bullet$ & & \\
\hline Ignoring alignment check suggestions & $\bullet$ & $\bullet$ & & $\bullet$ \\
\hline $\begin{array}{l}\text { Forgetting open panels, loose components, unfixed covers } \\
\text { (e.g. bolts) }\end{array}$ & $\bullet$ & $\bullet$ & & \\
\hline Gearbox bearing calibration failure & & $\bullet$ & & \\
\hline Unauthorized repairs/modifications & $\bullet$ & $\bullet$ & & \\
\hline $\begin{array}{l}\text { Improper torque application during fitting of couplings, } \\
\text { gearbox components, etc. }\end{array}$ & $\bullet$ & $\bullet$ & & $\bullet$ \\
\hline Operating beyond lubricant life & & $\bullet$ & & $\bullet$ \\
\hline Careless use of measurement devices & & $\bullet$ & & $\bullet$ \\
\hline Leave foreign object in gearbox (e.g. debris) & $\bullet$ & $\bullet$ & & $\bullet$ \\
\hline Omitted checklist item & $\bullet$ & $\bullet$ & & $\bullet$ \\
\hline Improper inspection & $\bullet$ & $\bullet$ & & \\
\hline Use of defected parts & $\bullet$ & $\bullet$ & & \\
\hline \multicolumn{5}{|l|}{ Inadequate organizational guidance } \\
\hline Poor decision by the technician & $\bullet$ & $\bullet$ & $\bullet$ & \\
\hline Loss of situational awareness by the technician & & $\bullet$ & & \\
\hline Procedural mistakes by the technician & $\bullet$ & $\bullet$ & & \\
\hline $\begin{array}{l}\text { Bending of regulations or standard maintenance procedure by } \\
\text { the technician }\end{array}$ & $\bullet$ & $\bullet$ & & $\bullet$ \\
\hline \multicolumn{5}{|l|}{ Organizational failure to enforce regulations } \\
\hline \multicolumn{5}{|l|}{ Organizational failure to track technician's performance } \\
\hline \multicolumn{5}{|l|}{ Poor planning of organization } \\
\hline \multicolumn{5}{|l|}{$\begin{array}{l}\text { Supervisory failure to inspect work done or other technician's } \\
\text { duties }\end{array}$} \\
\hline Omitting a step or more in the maintenance task sequence & $\bullet$ & $\bullet$ & & $\bullet$ \\
\hline Use of unauthorized materials/parts & $\bullet$ & $\bullet$ & & \\
\hline Time pressure & & & & \\
\hline
\end{tabular}

Table 10 Association of Resilience as Anticipating Component with OWT Risk Based Maintenance Management Systems 


\begin{tabular}{|c|c|c|c|c|c|c|c|c|}
\hline \multirow[b]{2}{*}{ Cause of Failures } & \multicolumn{8}{|c|}{ RESILIENCE AS ANTICIPATING } \\
\hline & Preparedness & $\begin{array}{l}\text { Vigilance } \\
\text { to risks }\end{array}$ & $\begin{array}{l}\text { Avoid making } \\
\text { assumptions }\end{array}$ & $\begin{array}{l}\text { Awareness and } \\
\text { Scenario thinking }\end{array}$ & $\begin{array}{l}\text { Getting little } \\
\text { things right }\end{array}$ & $\begin{array}{l}\text { Not to focus } \\
\text { individually }\end{array}$ & $\begin{array}{l}\text { Mindfulness to minor } \\
\text { potential problems }\end{array}$ & $\begin{array}{c}\text { Use } \\
\text { systematic } \\
\text { analysis }\end{array}$ \\
\hline Excessive/lower/wrong lubrication or greasing & & & & & & & & $\bullet$ \\
\hline $\begin{array}{l}\text { Inadequate technical information of the technician } \\
\text { about gearbox }\end{array}$ & & & & & $\bullet$ & $\bullet$ & & \\
\hline Improper cleaning during maintenance & & & & & & & & $\bullet$ \\
\hline Incorrect installation & & & & & & & & $\cdot$ \\
\hline Ignoring alignment check suggestions & & $\bullet$ & $\bullet$ & $\bullet$ & & $\bullet$ & $\bullet$ & $\cdot$ \\
\hline $\begin{array}{l}\text { Forgetting open panels, loose components, unfixed } \\
\text { covers (e.g. bolts) }\end{array}$ & & & & & & & $\bullet$ & $\bullet$ \\
\hline \multicolumn{9}{|l|}{ Gearbox bearing calibration failure } \\
\hline Unauthorized repairs/modifications & & $\bullet$ & $\bullet$ & $\bullet$ & & & & \\
\hline $\begin{array}{l}\text { Improper torque application during fitting of couplings, } \\
\text { gearbox components, etc. }\end{array}$ & & & & & & & $\bullet$ & \\
\hline Operating beyond lubricant life & & $\bullet$ & $\bullet$ & & & & $\bullet$ & \\
\hline \multicolumn{9}{|l|}{ Careless use of measurement devices } \\
\hline Leave foreign object in gearbox (e.g. debris) & & & & & & & $\bullet$ & $\bullet$ \\
\hline Omitted checklist item & & - & - & - & & & & - \\
\hline Improper inspection & & & & $\bullet$ & & & & - \\
\hline Use of defected parts & & $\bullet$ & $\bullet$ & $\bullet$ & $\bullet$ & & $\bullet$ & \\
\hline Inadequate organizational guidance & $\bullet$ & & & & $\bullet$ & & & \\
\hline Poor decision by the technician & & & $\bullet$ & & & $\bullet$ & $\bullet$ & \\
\hline Loss of situational awareness by the technician & & & & $\bullet$ & $\bullet$ & $\bullet$ & & \\
\hline Procedural mistakes by the technician & & & $\bullet$ & & & $\bullet$ & & $\cdot$ \\
\hline $\begin{array}{l}\text { Bending of regulations or standard maintenance } \\
\text { procedure by the technician }\end{array}$ & $\bullet$ & $\bullet$ & $\bullet$ & $\bullet$ & & & & \\
\hline Organizational failure to enforce regulations & $\bullet$ & & & & & & & \\
\hline $\begin{array}{lllll}\begin{array}{l}\text { Organizational failure } \\
\text { performance }\end{array} & \text { to track technician's } \\
\end{array}$ & $\bullet$ & $\bullet$ & & & & & & \\
\hline Poor planning of organization & $\bullet$ & $\bullet$ & & & & & & \\
\hline $\begin{array}{l}\text { Supervisory failure to inspect work done or other } \\
\text { technician's duties }\end{array}$ & $\bullet$ & $\bullet$ & & & & & & \\
\hline $\begin{array}{l}\text { Omitting a step or more in the maintenance task } \\
\text { sequence }\end{array}$ & & & & & & & $\bullet$ & $\bullet$ \\
\hline Use of unauthorized materials/parts & & $\bullet$ & $\bullet$ & $\bullet$ & $\bullet$ & & & \\
\hline Time pressure & $\cdot$ & $\bullet$ & & & & & & $\bullet$ \\
\hline
\end{tabular}

Table 11 Association of Resilience as Learning Component with OWT Risk Based Maintenance Management Systems 


\begin{tabular}{|c|c|c|c|c|c|c|c|}
\hline \multirow[b]{2}{*}{ Cause of Failures } & \multicolumn{7}{|c|}{ RESILIENCE AS LEARNING } \\
\hline & $\begin{array}{c}\text { Use captured } \\
\text { useful } \\
\text { feedbacks }\end{array}$ & $\begin{array}{l}\text { Having } \\
\text { redundancies } \\
\text { in place }\end{array}$ & $\begin{array}{l}\text { Learning } \\
\text { culture }\end{array}$ & $\begin{array}{l}\text { Adaptation to } \\
\text { future } \\
\text { requirements }\end{array}$ & $\begin{array}{c}\text { Use standard } \\
\text { operating } \\
\text { procedures (SOPs) }\end{array}$ & $\begin{array}{l}\text { Effective education, } \\
\text { training with simulation } \\
\text { studies and exercises }\end{array}$ & $\begin{array}{c}\text { Do not } \\
\text { confuse luck } \\
\text { and success }\end{array}$ \\
\hline Excessive/lower/wrong lubrication or greasing & $\bullet$ & & $\bullet$ & $\bullet$ & $\bullet$ & $\bullet$ & \\
\hline Inadequate technical information of the technician about gearbox & $\bullet$ & & $\bullet$ & $\bullet$ & & $\bullet$ & \\
\hline Improper cleaning during maintenance & $\bullet$ & & $\bullet$ & & $\bullet$ & $\bullet$ & \\
\hline Incorrect installation & & & $\bullet$ & $\bullet$ & $\bullet$ & $\bullet$ & \\
\hline Ignoring alignment check suggestions & & & & $\bullet$ & $\bullet$ & & $\bullet$ \\
\hline $\begin{array}{l}\text { Forgetting open panels, loose components, unfixed covers (e.g. } \\
\text { bolts) }\end{array}$ & & & & & $\bullet$ & $\bullet$ & \\
\hline Gearbox bearing calibration failure & $\bullet$ & & & & $\bullet$ & $\bullet$ & \\
\hline Unauthorized repairs/modifications & & & $\bullet$ & $\bullet$ & $\bullet$ & & $\bullet$ \\
\hline $\begin{array}{l}\text { Improper torque application during fitting of couplings, gearbox } \\
\text { components, etc. }\end{array}$ & $\bullet$ & & $\bullet$ & $\bullet$ & $\bullet$ & $\bullet$ & \\
\hline Operating beyond lubricant life & & $\bullet$ & & $\bullet$ & $\bullet$ & & \\
\hline Careless use of measurement devices & & & & $\bullet$ & & & \\
\hline Leave foreign object in gearbox (e.g. debris) & & & & & $\bullet$ & & \\
\hline Omitted checklist item & & & & $\bullet$ & $\bullet$ & & $\bullet$ \\
\hline Improper inspection & $\bullet$ & & $\bullet$ & & $\bullet$ & $\bullet$ & \\
\hline Use of defected parts & & $\bullet$ & & $\bullet$ & $\bullet$ & & $\bullet$ \\
\hline Inadequate organizational guidance & & & & $\bullet$ & & & \\
\hline Poor decision by the technician & $\bullet$ & & $\bullet$ & & $\bullet$ & $\bullet$ & \\
\hline \multicolumn{8}{|l|}{ Loss of situational awareness by the technician } \\
\hline Procedural mistakes by the technician & $\bullet$ & & & & $\bullet$ & $\bullet$ & \\
\hline $\begin{array}{l}\text { Bending of regulations or standard maintenance procedure by the } \\
\text { technician }\end{array}$ & & & & $\bullet$ & $\bullet$ & & $\bullet$ \\
\hline Organizational failure to enforce regulations & & & $\bullet$ & $\bullet$ & & & \\
\hline Organizational failure to track technician's performance & & & & $\bullet$ & & & \\
\hline Poor planning of organization & & & $\bullet$ & $\bullet$ & & & \\
\hline $\begin{array}{l}\text { Supervisory failure to inspect work done or other technician's } \\
\text { duties }\end{array}$ & $\bullet$ & & $\bullet$ & $\bullet$ & & & \\
\hline Omitting a step or more in the maintenance task sequence & & & & $\bullet$ & $\bullet$ & $\bullet$ & $\bullet$ \\
\hline Use of unauthorized materials/parts & & $\bullet$ & & $\bullet$ & $\bullet$ & & $\bullet$ \\
\hline Time pressure & & & & $\bullet$ & $\bullet$ & & \\
\hline
\end{tabular}

